\title{
Compendium of Grape Diseases, Disorders, and Pests SECOND EDITION
}

\author{
Edited by \\ Wayne F. Wilcox \\ Cornell University \\ New York State Agricultural Experiment Station, Geneva \\ Walter D. Gubler \\ University of California, Davis \\ Jerry K. Uyemoto \\ United States Department of Agriculture-Agricultural Research Service (retired) \\ University of California, Davis

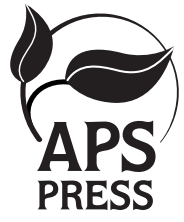

The American Phytopathological Society 
Front cover photograph: Andrew Hagen/Shutterstock.com

Back cover photographs (center, then clockwise from upper left): C. N. Austin, R. C. Pearson, W. F. Wilcox, T. B. Sutton, T. J. Burr, W. F. Wilcox, M. Fuchs, M. Sosnowski, and W. F. Wilcox

Reference in this publication to a trademark, proprietary product, or company name by personnel of the U.S. Department of Agriculture or anyone else is intended for explicit description only and does not imply approval or recommendation to the exclusion of others that may be suitable.

Library of Congress Control Number: 2015935134

International Standard Book Numbers:

Print: 978-0-89054-479-2

Online: $978-0-89054-481-5$

Mobi eBook: 978-0-89054-480-8

ePub eBook: 978-0-89054-552-2

(C) 1988, 2015 by The American Phytopathological Society

First edition published 1988

Second edition published 2015

Second printing, 2017

Second printing includes substantial technical corrections.

Third printing, 2019

All rights reserved.

No portion of this book may be reproduced in any form, including photocopy, microfilm, information storage and retrieval system, computer database, or software, or by any means, including electronic or mechanical, without written permission from the publisher.

Copyright is not claimed in any portion of this work written by U.S. government employees as a part of their official duties.

Copyright is not claimed in portions of this work (Figures 39, 89, 135, 175, 176, 177, 294, and 345, and the section on Sour Rot) created by an employee of Ontario Ministry of Agriculture and Food. (c) Queen's Printer for Ontario.

Printed in the United States of America on acid-free paper

The American Phytopathological Society

3340 Pilot Knob Road

St. Paul, Minnesota 55121, U.S.A. 


\section{Preface}

The first edition of the Compendium of Grape Diseases was published in 1988. It was a groundbreaking book at the time and has remained a major reference for grape growers and advisers ever since. However, the volume and breadth of grape disease research conducted in the quarter century following its publication, and the degree to which the results of these efforts have been utilized to improve vineyard disease management programs, is remarkable. Thus, our intention in compiling the second edition of this volume has been to preserve the basic structure and value of the original while reflecting the many advances that have been made in understanding the subject matter since that publication's release. In doing so, we have maintained a primary focus on multiple infectious diseases of grapes that are caused by fungi, oomycetes, bacteria, phytoplasmas, viruses, and viruslike agents, including the symptoms and diagnostic features for each of the diseases; the etiological agents and environmental conditions that interact with the host to cause them; and techniques for their management.

As with the first edition, we also have included a chapter on the parasitic nematodes that affect grapes and have provided photographs and text to help diagnose and understand the symptoms of various abiotic disorders. Similarly, we again have provided text and photographs to aid in diagnosing the symptoms that are caused by certain arthropod pests but can be mistaken for symptoms of infectious diseases, along with relevant information on the biology and management of those pests. To highlight its primary focus on infectious diseases while also recognizing this additional subject matter, the new volume has been titled Compendium of Grape Diseases, Disorders, and Pests. For more inclusive treatments of abiotic disorders and/or pests, the interested reader is encouraged to consult additional sources that examine these topics in greater detail.

Due to the significant international value of grapes, the wide range of diseases that afflict the crop, and the critical role that disease management plays in its production, this new edition is published in an expanded format that allows additional pages of text and figures beyond those accommodated in the original; included are 375 photographs and drawings, including 280 that are new to this edition. The book is intended to be a general reference that is accessible to individuals with limited formal training in plant pathology and its associated disciplines, while also providing sufficient technical detail to be of value to subject matter specialists. Nevertheless, it remains oriented toward a primary readership of informed grape growers, their advisers in the public and private sectors of the economy, and individuals in various support industries who wish to diagnose grape diseases and disorders and are seeking science-based, practical information regarding their cause and control. Two relatively extensive sections that were not included in the first edition, Grapevine Fungicides and Spray Technology for Grapevines, attest to this particular focus on grape producers and disease management practitioners. And in an effort to provide additional context pertaining to the host plant itself, two other sections have been expanded significantly relative to their counterparts in the first edition, (i) The Genus Vitis, Its Species, and Its Rootstocks; and (ii) Grapevine Structure and Growth Stages.

This book is a collaborative effort of 79 authors and coauthors who are recognized authorities in their fields. These authors represent 12 different countries spread across five continents, thereby providing a deliberate international scope and perspective to the information presented. Many of the individual authors contributed photographs for their own sections and sometimes for sections written by others as well. Photographs and illustrations new to this volume were provided by 29 additional individuals who did not author sections of the text, whom we thank and gratefully acknowledge below.

The Compendium of Grape Diseases, Disorders, and Pests rests squarely on the shoulders the first edition, Compendium of Grape Diseases. That original volume provided the fundamental framework for this current one, and we recognize and remember its editors, the late Drs. Roger C. Pearson (who was taken from us far too soon) and Austin C. Goheen. Many of the individual sections in the original edition provided a basis for the revised versions in this new one, and we recognize and thank the previous contributors, who are listed below. Additionally, we thank Gary Grove and Heather Scheck for critically reviewing the entire manuscript; Marc Fuchs and Naidu Rayapati for their thorough reviews and prepublication updates of the chapter on virus diseases; and Bob Martin and the staff of APS PRESS for their editorial assistance in getting the book completed.

Contributors to the first edition:

M. Bisiach, Universita degli Studi della Tuscia, Viterbo, Italy

J. Bulit, Institut National de la Recherche Agronomique,

Centre de Recherches de Bordeaux, Pont-de-la-Maye, France T. J. Burr, New York State Agricultural Experiment Station, Cornell University, Geneva, New York, U.S.A.

M. V. Carter, The University of Adelaide, Waite Agricultural

Research Institute, Glen Osmond, South Australia

A. Caudwell, Institut National de la Recherche Agronomique, Dijon, France

L. P. Christensen, University of California, Kearney Agricultural Center, Parlier, California, U.S.A.

M. Clerjeau, Institut National de la Recherche Agronomique, Centre de Recherches de Bordeaux, Pont-de-la-Maye, France

B. Dubos, Institut National de la Recherche Agronomique, Centre de Recherches de Bordeaux, Pont-de-la-Maye, France

D. L. Flaherty, University of California Cooperative Extension, Visalia, California, U.S.A.

J. A. Foster, USDA-APHIS-PPQ, U.S. Plant Quarantine Facility, Glenn Dale, Maryland, U.S.A.

P. Galet, Ecole Nationale Supérieure Agronomique de Montpellier, France

W. Gärtel, Biologische Bundesanstalt für Land- and Forstwirtschaft, Institut für Pflanzenschutz im Weinbau, Bernkastel-Kues, Federal Republic of Germany

A. C. Goheen, University of California, Davis, California, U.S.A. 
D. Gonsalves, New York State Agricultural Experiment Station, Cornell University, Geneva, New York, U.S.A.

J. Granett, University of California, Davis, California, U.S.A.

T. Herrera, Centro de Investigaciones Agricolas del Norte, Campo Agricola Experimental de la Laguna, Torreon, Coah., Mexico

W. B. Hewitt, University of California, Davis, California, U.S.A.

D. L. Hopkins, University of Florida, Leesburg, Florida, U.S.A.

G. L. Jubb, Jr., University of Maryland, Keedysville, U.S.A.

A. N. Kasimatis, University of California, Davis, California, U.S.A.

R. Lafon, Institut National de la Recherche Agronomique, Centre de Recherches de Bordeaux, Pont-de-la-Maye, France

P. Larignon, Institut National de la Recherche Agronomique, Centre de Recherches de Bordeaux, Pont-de-la-Maye, France

J. Lehoczky, Plant Protection Institute, Hungarian Academy of Sciences, Budapest, Hungary

L. S. Leu, Taiwan Agricultural Chemicals and Toxic Substances Research Institute, Taichung Hsien Taiwan, Republic of China

S. D. Lyda, Texas A\&M University, College Station, Texas, U.S.A.

G. P. Martelli, Universita Degli Studi di Bari, Bari, Italy

J. R. McGrew, Hanover, Pennsylvania, U.S.A.

R. D. Milholland, North Carolina State University, Raleigh, North Carolina, U.S.A.

S. M. Mircetich, USDA, University of California, Davis, California, U.S.A.

I. I. Mirică, Staţiunea de Cercetare şi Producţie Viti-vinicolă, Argeş, Rumania

L. T. Morton, Broad Run, Virginia, U.S.A.

S. Nelson-Kluk, Foundation Seed and Plant Materials Service, University of California, Davis, California, U.S.A.

C. G. Panagopoulos, Athens College of Agricultural Sciences, Athens, Greece

R. C. Pearson, New York State Agricultural Experiment Station, Cornell University, Geneva, New York, U.S.A.

F. G. Pollack, Naples, Florida, U.S.A.

R. M. Pool, New York State Agricultural Experiment Station, Cornell University, Geneva, New York, U.S.A.

C. Pratt, New York State Agricultural Experiment Station, Cornell University, Geneva, New York, U.S.A.

R. D. Raabe, University of California, Berkeley, California, U.S.A.

D. C. Ramsdell, Michigan State University, East Lansing, Michigan, U.S.A.

D. J. Raski, University of California, Davis, California, U.S.A.

V. Savino, Universita Degli Studi di Bari, Bari, Italy

W. C. Schnathorst, University of California, Davis, California, U.S.A.

H. Schöffling, Landes- Lehr- und Versuchsanstalt für Landwirtschaft, Weinbau und Gartenbau, Trier, Federal Republic of Germany

H. Schüepp, Eidgenössische Forschungsanstalt für Obst-, Wein- und Gartenbau, Wädenswil, Switzerland

G. Stellmach, Biologische Bundesanstalt für Land- und Forstwirtschaft, Institut für Pflanzenschutz im Weinbau, Bernkastel-Kues, Federal Republic of Germany

L. H. Weinstein, Boyce Thompson Institute for Plant Research at Cornell University, Ithaca, New York, U.S.A.

W. F. Wilcox, New York State Agricultural Experiment Station, Cornell University, Geneva, New York, U.S.A.

R. N. Williams, Ohio State University, Ohio Agricultural Research and Development Center, Wooster, Ohio, U.S.A.
L. T. Wilson, University of California, Davis, California, U.S.A.

New photographs or illustrations provided by:

Craig N. Austin, DuPont Crop Protection, Newark, Delaware, U.S.A.

Terrence Bates, Cornell University, Portland, New York, U.S.A.

M. Bisiach (deceased), University of Milan, Milan, Italy

Lailang Cheng, Cornell University, Ithaca, New York, U.S.A.

Andrew M. Daly, CSIRO, Darwin, Northern Territory, Australia

Richard M. Dunst, Cornell University, Portland, New York, U.S.A.

Connie L. Fisk, North Carolina State University, Raleigh, North Carolina, U.S.A.

Sobhi M. Girgis, National Agricultural Research Foundation, Athens, Greece

Bradley D. Hanson, University of California, Davis, California, U.S.A.

Stephen Hessler, Cornell University, Geneva, New York, U.S.A.

Harvey C. Hoch, Cornell University, Geneva, New York, U.S.A.

James S. Kamas, Texas A\&M University, College Station, Texas, U.S.A.

Markus Keller, Washington State University, Prosser, Washington, U.S.A.

L. R. Krake, CSIRO, Adelaide, South Australia, Australia

George M. Leavitt, University of California Cooperative Extension, Madera, California, U.S.A.

Pascal Lecomte, INRA, Villenave d'Ornon, France

Timothy E. Martinson, Cornell University, Geneva, New York, U.S.A.

Maxwell Norton, University of California Cooperative Extension, Merced, California, U.S.A.

Satoshi T. Ohki, Osaka Prefecture University, Sakai, Osaka, Japan

Roger C. Pearson (deceased), Cornell University, Geneva, New York, U.S.A.

Cristina Pisani, University of California, Davis, California, U.S.A.

John Roncoroni, University of California Cooperative Extension, Napa, California, U.S.A.

Annemiek Schilder, Michigan State University, East Lansing, Michigan, U.S.A.

Nadja Schoepe, Staatliches Weinbauinstitut, Freiburg, Germany

Andrew Senesac, Cornell University, Riverhead, New York, U.S.A.

Michael White, Iowa State University, Ames, Iowa, U.S.A.

Mary Jean Welser, Cornell University, Geneva, New York, U.S.A.

Alice Wise, Cornell University Cooperative Extension, Riverhead, New York, U.S.A.

Stella M. Zitter, Cornell University, Geneva, New York, U.S.A.

Finally, we recognize the contributions of countless researchers, technicians, students, laborers, grape growers, and vineyard advisers whose work and observations have contributed to the body of knowledge reflected in these pages, but whose names do not appear within.

Wayne F. Wilcox W. Douglas Gubler Jerry K. Uyemoto 


\section{Contributors}

We gratefully acknowledge those who prepared new or revised sections for the 2nd Edition of this Compendium.

David N. Appel

Texas A\&M University

College Station, Texas, U.S.A.

Apostolos D. Avgelis

Plant Protection Institute

Heraklion, Crete, Greece

Kendra Baumgartner

USDA-ARS

University of California

Davis, California, U.S.A.

Donato Boscia

Institute of Plant Virology

National Research Council

Turin, Italy

Elisabeth Boudon-Padieu

INRA CNRS

Université de Bourgogne

Dijon, France

Thomas J. Burr

Cornell University

Geneva, New York, U.S.A.

Fiona E. Constable

Department of Environment and

Primary Industries

Melbourne, Victoria, Australia

Paolo Cortesi

University of Milan

Milan, Italy

Peter Cousins

E. \& J. Gallo Winery

Modesto, California, U.S.A.

Kent M. Daane

University of California

Berkeley, California, U.S.A.

Jacqueline Edwards

Department of Environment and

Primary Industries

Melbourne, Victoria, Australia

Mike A. Ellis

The Ohio State University

Wooster, Ohio, U.S.A.
Akif Eskalen

University of California

Riverside, California, U.S.A.

Howard Ferris

University of California

Davis, California, U.S.A.

Joseph A. Foster

USDA-APHIS-PPQ

Beltsville, Maryland, U.S.A.

Marc Fuchs

Cornell University

Geneva, New York, U.S.A.

David M. Gadoury

Cornell University

Geneva, New York, U.S.A.

R. Garau

University of Sassari

Sassari, Italy

Carmen Gispert

University of California Cooperative

Extension

Indio, California, U.S.A.

Martin C. Goffinet

Cornell University

Geneva, New York, U.S.A.

Deborah A. Golino

Foundation Plant Services

University of California

Davis, California, U.S.A.

Jeffrey Granett

University of California

Davis, California, U.S.A.

W. Douglas Gubler

University of California

Davis, California, U.S.A.

Paul Gugerli

Agroscope Changins-Wädenswil ACW

Nyon, Switzerland

David R. Haviland

University of California Cooperative

Extension

Bakersfield, California, U.S.A.
Georg K. Hill

DLR-Rheinhessen-Nahe-Hunsrück Oppenheim, Germany

Lisa E. Hoffman

DuPont Crop Protection

Newark, Delaware, U.S.A.

Raymond Johnson

Agriculture and Agri-Food Canada

Sidney, British Columbia, Canada

Hanns-Heinz Kassemeyer

Staatliches Weinbauinstitut

Freiburg, Germany

Bruce C. Kirkpatrick

University of California

Davis, California, U.S.A.

Andrew J. Landers

Cornell University

Geneva, New York, U.S.A.

Bernardo Latorre

P. Universidad Católica de Chile

Santiago, Chile

Alan Little

University of Adelaide

Adelaide, Australia

Gregory Loeb

Cornell University

Geneva, New York, U.S.A.

Walter F. Mahaffee

USDA-ARS

Oregon State University

Corvallis, Oregon, U.S.A.

Michael Maixner

Julius Kühn-Institut

FRI Cultivated Plants

Siebeldingen, Germany

Giovanni P. Martelli

Università degli Studi di Bari

Bari, Italy

Sheila A. McBride

Texas A\&M University

College Station, Texas, U.S.A. 
Wendy McFadden-Smith

Ontario Ministry of Agriculture, Food, and Rural Affairs

Vineland Station, Ontario, Canada

Michael V. McKenry

University of California

Parlier, California, U.S.A.

Angelantonio Minafra

Instituto di Virologia Vegetale del CNR

Bari, Italy

Laura Mugnai

University of Florence

Florence, Italy

Francesca Peduto Hand

The Ohio State University

Columbus, Ohio, U.S.A.

Elsa Petit

Université Paris-Sud

Orsay, France

Alan J. L. Phillips

Universidade Nova de Lisboa

Caparica, Portugal

Charlotte Pratt (deceased)

Cornell University

Geneva, New York, U.S.A.

Ulisse Prota

University of Sassari

Sassari, Italy

Jay W. Pscheidt

Oregon State University

Corvallis, Oregon, U.S.A.

Belinda Rawnsley

Peracto SA

Adelaide, South Australia, Australia

M. Ali Rezaian

CSIRO

Adelaide, South Australia, Australia

David M. Rizzo

University of California

Davis, California, U.S.A.
Philippe E. Rolshausen

University of California

Riverside, California, U.S.A.

Amy Y. Rossman

USDA-ARS

Beltsville, Maryland, U.S.A.

Joachim Rumbolz

GAB Consulting

Lamstedt, Germany

Sead Sabanadzovic

Mississippi State University

Mississippi State, Mississippi, U.S.A.

Pasquale Saldarelli

Department of Biology Agriculture and Food Science

National Research Council

Oristano, Italy

Vito Savino

Università degli Studi di Bari

Bari, Italy

Mark R. Sosnowski

South Australian Research and

Development Institute

Adelaide, South Australia, Australia

Mysore R. Sudarshana

University of California

Davis, California, U.S.A.

Giuseppe Surico

University of Florence

Florence, Italy

Turner B. Sutton

North Carolina State University

Raleigh, North Carolina, U.S.A.

Yasuo Terai

Yamanashi Prefectural Agricultural Academy

Yamanashi, Japan

Tarlochen S. Thind

Punjab Agricultural University

Ludhiana, India
Florent Pierre Trouillas

University of California

Parlier, California, U.S.A.

Jose Ramon Urbez Torres

Agriculture and Agri-Food Canada

Summerland, British Columbia, Canada

Jerry K. Uyemoto

USDA-ARS

University of California

Davis, California, U.S.A.

Justine Vanden Heuvel

Cornell University

Ithaca, New York, U.S.A.

M. Andrew Walker

University of California

Davis, California, U.S.A.

Vaughn Walton

Oregon State University

Corvallis, Oregon, U.S.A.

Wayne F. Wilcox

Cornell University

Geneva, New York, U.S.A.

Tony K. Wolf

Virginia Polytechnic Institute

Winchester, Virginia, U.S.A.

Francis P. Wong

Bayer CropScience LP

Research Triangle Park, North

Carolina, U.S.A.

Frank G. Zalom

University of California

Davis, California, U.S.A.

Inga A. Zasada

USDA-ARS

Oregon State University

Corvallis, Oregon, U.S.A. 


\title{
Thank You to the Sponsors of the Compendium of Grape Diseases, Disorders, and Pests, Second Edition
}

\begin{abstract}
APS PRESS has designed this compendium series of practical guidebooks to offer convenient help in identifying, managing, and preventing the diseases of major crop plants. This compendium serves the interests of growers, consultants, and researchers. Financial sponsors allow these books to be more affordable to a wide audience.
\end{abstract}

APS PRESS thanks the following sponsors for their financial support of this compendium.

\author{
BASF \\ Dow AgroSciences \\ E\&J Gallo Winery \\ JMS Flower Farms, Inc. \\ Syngenta
}

